\title{
Demand Forecasting for Domestic Air Transportation in Turkey
}

\author{
Orhan Sivrikaya* and Enar Tunç
}

\author{
Department of Management, Okan University, Tuzla, Istanbul
}

\begin{abstract}
Accuracy in estimating air transport demand is a key element while an aviation company is planning its short term or long term business plan regardless of its status, being an incumbent or a startup company. Domestic Air Travel Industry in Turkey has dramatically grown in recent years especially after the deregulation which resulted in the renewal of air transportation policy in 2003. However, there is no relevant scientific research in the literature to analyze the determining factors on air travel demand for domestic market by city pair level in Turkey. A semi-logarithmic regression model is generated in order to estimate the domestic air travel demand in means of number of passengers carried per city pair. Airline passenger data of 2011 out of 42 served cities in Turkey are used to establish the model. Then, 2010 data are used to test the prediction performance of the model. Accuracy level is found to be significantly successful on estimating passenger demand for any domestic city pair. Due to its city pair basis and acceptable level of accuracy, the estimation model can be utilized in many areas of aviation industry, such as determining flight frequency on a route, forecasting the size of air passenger traffic for potential new airports or potential new routes etc.
\end{abstract}

Keywords: Domestic air transportation, city pair, origin and destination, connection time, travel time, gravity model, deregulation, multivariate linear regression and semi logarithmic regression.

\section{INTRODUCTION}

The deregulation of air transportation market in Turkey in 2003 has started revolutionary changes in the airline industry. New government having the target to increase the portion of air travel out of all modes of local transportation attempted to encourage more airline companies to enter into the domestic market. New aviation policy also enabled them to offer more attractive ticket prices due to tax cutting measures specific to the airline industry. Price oriented competition has worked very well, significantly increasing airline passenger traffic. Low cost carriers have contributed to a continuous two-digit growth by stealing passenger traffic from bus transportation companies as a result of closing the gap between relative prices. Turkish Airlines as a legacy carrier has responded to these structural changes in the domestic market by applying dynamic pricing policy and growth strategy to benefit from economies of scale coupled with efficiency in operations.

Big changes in airline passenger traffic in Turkey created a challenge in applying a model built to estimate air travel demand. Macroeconomic or demographic changes do not seem to be the only responsible drivers for the increase in air travel demand. Competition resulted in the increase in available seat capacity with new comers on some routes. This, in turn, forced airline companies to formulate a different strategy to generate additional demand to utilize the extra capacity in order to achieve in satisfactory load factor, a key performance indicator for airline profitability.

*Address correspondence to this author at the Department of Management, Okan University, Tuzla, Istanbul; Tel: +90-212-2126526;

Fax: 90-212-2662279; E-mail: osivrikaya@live.com
Airline traffic is considered as a significant indicator for the performance of the nation's entire industry since it is highly correlated with the number of business events and interactions with other industries. Hence, it implies that changes in economies might influence airlines traffic indirectly. However, airline specific parameters like ticket price and degree of competition are also known to be key drivers for air passenger demand.

The sustainable success of any organization or company is closely related with how well management or decision makers are able to foresee the future and develop appropriate strategies. The objective of this study is to examine the demand size for domestic air transport in Turkey and show its implications for air transport planning.

\section{BACKGROUND}

It has been seen throughout the results of the previous research in the literature that one of the most important issues to develop a predictive model is to choose the right combination of the variables which represent the determining factors involved in the model. These variables are categorized by two subgroups according to [1]: 1. Geoeconomics Factors: which consist of geographical characteristics, economical activities, social factor etc. 2. Service Related Factors: which are related to airline dependent factors.

The other prominent aspect of model generation is the level of forecast which can be classified by two groups: 1 . Microscopic Model: Airport specific or city pair specific data are involved such as the total number of incoming and outgoing passengers per particular airport or per city pair. 2 . Macroscopic Model: Region or country specific data are involved such as aggregate number of passengers in a region or country regardless of origin or destination city. 
Local area information appears to be more relevant in determining local O\&D travel than of national information such as gross domestic product [2]. Factors representing the industry associated with factors that are specific to a region are critically important for the existence of aviation companies as a whole. All these imply that local economics play a significant role in the development of air transport industry.

Due to lack of data, aviation companies used to apply top-down macro econometric models in demand forecasting. These models are unable to describe and analyze complex and dynamic route networking [2]. Recently, structural econometric models at micro scale such as $\mathrm{O}$ and $\mathrm{D}$ (Origin and Destination) level can be used as a result of significant advances in Management Information System (MIS) of the companies.

A variety of different models exist for airline passenger volume estimation. Since no single model guarantees accuracy, airlines compare forecasts from several different models. Amongst the existing set of forecasting methods, the most commonly used demand models are of the simple gravity type formulation [3]. Gravity type of functional formulation can be easily transformed to logarithmic expression so that multivariate regression model is applicable.

\section{OVERVIEW OF THE FACTOR AFFECTING AIR PASSENGER DEMAND IN TURKEY}

Turkey is spread over a wide geographical area and road ways are not adequately constructed for all directions. Therefore, potential traffic for domestic air transportation is supposed to have more shares compared to other transportation modes. While the gap between relative prices amongst the alternative modes of transportation has been rapidly closing, more and more people are expected to find air travel choice more affordable.

This study aims to find out the determining factors turning potential demand into air travel passengers. Population, gross domestic product per capita and distance are considered as the leading geo-economics dynamics behind air travel demand as depicted in Table 1. Average price has a stimulating effect on airline demand as [4] pointed out that ticket price is an elastic driver for airline demand generation. However, most of the related studies have used top-down macro econometric models. Therefore, one can expect that the significance of the variables can be different in micro level econometric models. Additionally, macro-economic variables are more likely to be highly correlated with each other because of their concurrences in an economic progress.
Table 1. Commonality in Types of Variables

\begin{tabular}{|l|c|l|}
\hline Variable's Name* & Number of Repeat & \multicolumn{1}{|c|}{ Reference Articles } \\
\hline \hline Population & 11 & {$[2-3,5-7,10-11,13-16]$} \\
\hline GDP & 9 & {$[5-8,9-11,15-16]$} \\
\hline Distance & 5 & {$[2,8,11,14-15]$} \\
\hline Travel Time & 5 & {$[3,5,11,13-14]$} \\
\hline GDP per Capita & 4 & {$[6,9,10,12]$} \\
\hline Price & 5 & {$[8,12,14-16]$} \\
\hline Service Frequency & 4 & {$[5,7-8,15]$} \\
\hline CPI & 3 & {$[6,9-10]$} \\
\hline Import Volume & 3 & {$[6,9-10]$} \\
\hline Employment & 2 & {$[1,7]$} \\
\hline Exchange Rate & 2 & {$[9-10]$} \\
\hline Cost & 2 & {$[3,5]$} \\
\hline Expenditures & 2 & {$[9-10]$} \\
\hline Fuel Price & 1 & {$[1]$} \\
\hline
\end{tabular}

* The most common variables are listed out of a sample of 15 different relevant articles.

As it is shown in Table 2, geo-economics factors are mostly related to each other. Where, values of variables are calculated by taking the product of the corresponding values for origin and destination cities. GDP values of cities are not available for the period of sample data because Bureau of State Statistics of Turkey has stopped to record city level GDP since 2001. Therefore, GDP values are estimated by assuming that GDP contribution of the cities should remain the same since 2001. In order to avoid multicollinearity problem, bedding capacity and population were selected as the best representing and reliable variables amongst the other geo-economics variables export volume, GDP and intercity migrants which are all highly correlated with population.

Independent variables are listed in Table $\mathbf{3}$ where $\mathrm{i}$ and $\mathrm{j}$ stand for the cities $\mathrm{i}$ and $\mathrm{j}$. Population, bedding capacity and distance are classified as geo-economics factors expected to have positive impact on air passenger demand. The reason for the positive impact of distance on airline passenger demand is due to the fact that the gap between relative travel times is getting higher for longer distance in favor of air transportation mode. All other independent variables are airline specific. Airlines related factors can be considered surrogate variables

Table 2. Correlation Matrix for Geo-Economics Factors

\begin{tabular}{|c|c|c|c|c|c|}
\hline & GDP & Bedding Capacity & Export Volume & Population & Intercity Migrants \\
\hline \hline GDP & 1.0000 & 0.1881 & 0.8679 & 0.9726 & 0.8246 \\
\hline Bedding Capacity & 0.1881 & 1.0000 & 0.0773 & 0.1467 & 0.1633 \\
\hline Export Volume & 0.8679 & 0.0773 & 1.0000 & 0.8680 & 0.6661 \\
\hline Population & 0.9726 & 0.1467 & 0.8680 & 1.0000 & 0.8004 \\
\hline Intercity Migrants & 0.8246 & 0.1633 & 0.6661 & 0.8004 & 1.0000 \\
\hline
\end{tabular}


for airline passenger preference. Transit (as a dummy variable "O" means direct service and " 1 " means connecting service for a city pair), price, travel time are expected to have negative effect, whereas airline count, travel match and schedule consistency are expected to have positive effect on air passenger demand. These air service specific variables are not only driving factors for airline market share in a competitive flight route, but also showing induced effects for shifting additional customer from other modes of transportation. Schedule consistency represents seasonality of air service. Air service, which is not available for whole year, is to generate reduced passenger traffic due to lack of consistent service and consequently restricted market penetration. Airline count indicates market structure of the underlying route. Air carriers apply different business strategy depending on market form. Monopolistic airlines focus on yield improvement, whereas oligopolists seek for a better market share. These two different policies obviously influence air travel demand in opposite manner. The travel match is reflecting round trip effect of the flight schedule for a city pair. It is simply calculated by dividing the product of number of scheduled days for outgoing and incoming week by the maximum value of the corresponding denominator which is equal to 49. According to the best knowledge of the authors, the travel match is here introduced first time in the literature to be employed in demand forecasting model for air transportation. It indicates the matching probability of a travel plan with available flights in days of week for both onward and backward direction. The travel match increases by square of the number of weekly scheduled flights, so weak frequency of service would be reasonably less attractive especially for air traveler who frequently flies for business purposes.

\section{ECONOMETRIC ESTIMATION DATA, METHODO- LOGY AND RESULTS}

\section{The Data}

The model used in this study is not only to explain actual traffic results between on-line (existing) domestic cities but also to estimate potential traffic for off-line domestic cities where either no airport or idle airport is available.
Data availability is the main issue when data coverage is to be decided. In our study, experimental model is based on the data from 2011 for which data for all explanatory variables are available. There were 42 on-line cities in domestic network in Turkey in 2011. With this data set, we can theoretically generate 1722 different combinations of origin and destinations (O\&D's). The actual number of O\&D's was reduced to 861 cities by rearranging O\&D's regardless of their direction. Eventually, the experimental data do not cover such number of city pairs. For some city pairs, there are no air services or the connecting flights are not meaningful due to longer travel times. In the experimental data, there are 239 city pairs with actual traffic results. 69 city pairs are served by direct flights whereas the remaining 170 city pairs are found to be flown by connecting flights via an appropriate domestic hub.

Route statistics for all scheduled carriers are used in the experimental model as a source of the dependent variable. Transfer traffic is removed from the statistics for each city pair, since the model is to estimate pure O\&D passenger demand by referring to the independent variables specific to the corresponding city pair. Airline specific data were provided by Director General Civil Aviation of Turkey. Road distances between the cities were taken from the web site of the General Directorate Highways of Turkey. Population and bedding capacity of the cities were retrieved from the web site of State Statistics Bureau of Turkey.

\section{The Model}

A comprehensive review of researches on air passenger demand forecasting was presented by [17]. A demand model for scheduled air carrier services was formed for the whole network of international European routes in 1989. The estimated model covered the variables describing both the geo-economic characteristics of the region where transportation took place and the patterns of airline service, as determined by flight frequency, aircraft size and air fares. Reference [4] collected 37 studies and 204 observations, and showed that the demand for air travel is largely determined by the spending capacity of customers. Later, reference [11] presented two gravity models for air passenger volume

Table 3. Independent Variables

\begin{tabular}{|c|c|c|}
\hline Notation & Functional Specification & Factor \\
\hline \hline $\mathrm{P} o p_{\mathrm{i} j}$ & $\mathrm{P} o p_{\mathrm{i}} \times \mathrm{P} o p_{\mathrm{j}} \times 10^{-6}$ & Urban Population \\
\hline $\mathrm{B} e d_{\mathrm{i} j}$ & $\mathrm{~B} e d_{\mathrm{i}} \times \mathrm{B} e d_{\mathrm{j}} \times 10^{-3}$ & Bedding Capacity \\
\hline $\mathrm{D} s t_{\mathrm{i} j}$ & Distance by road & Distance \\
\hline $\mathrm{T} r t_{\mathrm{i} j}$ & Dummy variable $(0$ or 1$)$ & Transit \\
\hline $\mathrm{P} r c_{\mathrm{i} j}$ & Average airline ticket price & Airline Count \\
\hline $\mathrm{C} n t_{\mathrm{i} j}$ & Number of airlines on the route & Travel Match \\
\hline $\mathrm{T} r m_{\mathrm{i} j}$ & Percentage of flight choices matching a travel plan & Schedule Consistency \\
\hline $\mathrm{S} c d_{\mathrm{i} j}$ & Number of months that flight service is available & Travel Time \\
\hline $\mathrm{T} t m_{\mathrm{i} j}$ & Time elapsed between starting and ending time of travel & \\
\hline
\end{tabular}


forecasting between city-pairs. The models used mainly geoeconomics variables rather than service related factors. The model moderately showed a good fit to the observed data which contains 1228 city-pairs with 137 embracing cities.

The gravity model takes the form:

$$
Y=\alpha X_{1}^{\beta_{1}} X_{2}^{\beta_{2}} X_{3}^{\beta_{3}} \ldots
$$

This model assumes that the marginal effects of each variable on demand are not constant but depend on both the value of the variable and the values of all other variables in the demand function [18]. In other words, the explanatory variables affect demand in multiplicative manner. Partial derivation of any independent variable proves aforementioned relationship. However, this model can be made suitable for multiple regressions by applying logarithmic transformation. Logarithmic form of the gravity model takes the form:

$$
\log Y=\beta_{0}+\beta_{1} \log X_{1}+\beta_{2} \log X_{2}+\beta_{3} \log X_{3}+\ldots,
$$

where $\beta_{0}=\log \alpha$

It is obvious that interdependency is resolved in this form so that multiple regression model can be applied.

Following the demand function used by [18], this study specifies the demand for air travel service as a function of geo-economics and industry related factors depicted in Table 3. Based on the theoretical foundation, the original form of the demand model in this study is written as follows from origin $\mathrm{i}$ to destination $\mathrm{j}$ :

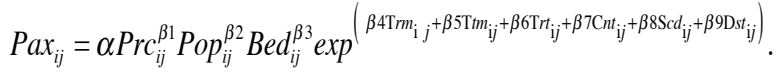

The linearized form is then specified as:

$$
\begin{aligned}
\operatorname{LogPax}_{i j}= & \beta_{0}+\beta_{1} \operatorname{LogPrc}_{i j}+\beta_{2} \operatorname{LogPop}_{i j}+\beta_{3} \operatorname{LogBed}_{i j}+ \\
& \beta_{4} \operatorname{Trm}_{i j}+\beta_{5} \operatorname{Ttm}_{i j}+\beta_{6} \operatorname{Trt}_{i j}+\beta_{7} \operatorname{Cnt}_{i j}+\beta_{8} \operatorname{Scd}_{i j}+ \\
& \beta_{9} \operatorname{Dst}_{i j},
\end{aligned}
$$

where $\mathrm{i}$ and $\mathrm{j}$ represent origin and destination city, and $\beta_{i^{\prime}} s$ are the coefficients of independent variables. The variables are defined as follows for each $\mathrm{i}$ and $\mathrm{j}$ :

$\operatorname{LogPax}_{i j}:$ Logarithmic transformation of the number of air passengers,

$\operatorname{Trm}_{\mathrm{i} j}$ : Matching probability of travel plan with available weekly flights,

$\mathrm{T}_{\mathrm{i}} m_{\mathrm{ij}}$ : Elapsed time between the start and end point of the journey,

$\operatorname{Trt}_{\mathrm{ij}}$ : Dummy variable indicating connection type; 0 for direct service and 1 otherwise,

$\mathrm{C}_{\mathrm{i} j}$ : Number of airlines serving on the route,

$\log \operatorname{Pr}_{\mathrm{ij}}$ : Logarithmic transformation of the average ticket price,

$\mathrm{Scd}_{\mathrm{ij}}$ : Continuity of flight service in number of months in a year,
$\operatorname{LogBed}_{\mathrm{ij}}:$ Logarithmic transformation of the product of the numbers of available beds in tourism facility,

$\operatorname{LogPop}_{\mathrm{i} j}:$ Logarithmic transformation of the product of cities population and

Dst $t_{\mathrm{ij}}$ : Road distance.

The statistical tool SAS Jmp 10 is utilized in this research. Semi-logarithmic regression model, which is a derived version of gravity model, is generated by using sample data of 2011 and prediction performance of the generated model is assessed by using testing data of 2010 .

The service specific factors, which can be generalized as airline service related aspects representing air travel demand attractiveness, travel match, travel time, transit, price, airline count and schedule consistency are embedded in the model in addition to the macro economic factors which are population, distance and the bedding capacity of the cities.

\section{The Results}

Table 4 shows the matrix of correlation between the independent variables. The results show that some of the variables are interrelated. For example, LogPop has the correlation coefficients -0.7135 and -0.6591 with travel time and transit respectively. However, these relatively high correlation coefficients do not mean a certain relation of causality; on the contrary, they may concur in the specified period simultaneously without a cause and effect interaction. Furthermore, the listed Variance Inflation Factors (VIF) for coefficents of independent variables in Table 7 support abovementioned interpretation since all independent variables have smaller VIF values than 5, which suggest that multicollinearity problem is not expected.

Adjusted $\mathrm{R}^{2}$ as shown in Table $\mathbf{5}$ is 0.86 which is fairly good. In Table 6 , adjusted $\mathrm{R}^{2}$ 's are benchmarked in comparison with the relevant articles in the reference list. This comparison table shows that the studied model efficiency is relatively successful. The F test also shows that the regression model is globally significant at a level less than 0.0001 .

As it is shown in Table 6, micro level forecast (O\&D) relatively underperforms macro level forecast (Aggregate) since the forecasting power lost by regressing heterogeneous information across city pairs is dominated by the forecasting power gained due to the fact that aggregation cancels out individual forecasting errors.

The built MLR (Multivariate Linear Regression) model is tested for its expected normality and homoscedasticity aspects: Shapiro-Wilk W Test for normality of the residuals has shown that the null hypothesis that the data comes from a normally distributed population cannot be rejected with the p-value of 0.2256, and Breush Pagan Test failed to reject the null hypothesis, which says that the model is homoscedastic, with the $p$-value of 1.0 for the F-test.

In Table 7, parameter estimates are depicted. As seen in the table, all independent variables are significant at 0.05 level. Since the coefficients of the logarithmic regression model represent elasticity of the corresponding independent 
Table 4. Correlation Matrix

\begin{tabular}{|c|c|c|c|c|c|c|c|c|c|}
\hline & Trm & Ttm & Trt & Cnt & $\log ($ Prc $)$ & Scd & $\log ($ Pop) & $\log ($ Bed $)$ & Dst \\
\hline \hline Trm & 1.0000 & -0.3860 & -0.1856 & 0.1663 & 0.1994 & -0.0004 & 0.2999 & 0.2346 & -0.1630 \\
\hline Ttm & -0.3860 & 1.0000 & 0.6528 & -0.4673 & -0.3203 & 0.0858 & -0.7135 & -0.5655 & -0.1074 \\
\hline Trt & -0.1856 & 0.6528 & 1.0000 & -0.2953 & -0.2061 & 0.2118 & -0.6591 & -0.2795 & -0.0139 \\
\hline Cnt & 0.1663 & -0.4673 & -0.2953 & 1.0000 & 0.3020 & 0.0981 & 0.5363 & 0.4170 & 0.1820 \\
\hline Log(Prc) & 0.1994 & -0.3203 & -0.2061 & 0.3020 & 1.0000 & 0.1329 & 0.3576 & 0.2544 & 0.0598 \\
\hline Scd & -0.0004 & 0.0858 & 0.2118 & 0.0981 & 0.1329 & 1.0000 & -0.0691 & -0.0199 & 0.0106 \\
\hline Log(Pop) & 0.2999 & -0.7135 & -0.6591 & 0.5363 & 0.3576 & -0.0691 & 1.0000 & 0.4653 & -0.1288 \\
\hline Log(Bed) & 0.2346 & -0.5655 & -0.2795 & 0.4170 & 0.2544 & -0.0199 & 0.4653 & 1.0000 & 0.1112 \\
\hline Dst & -0.1630 & -0.1074 & -0.0139 & 0.1820 & 0.0598 & 0.0106 & -0.1288 & 0.1112 & 1.0000 \\
\hline
\end{tabular}

Table 5. Summary of Fit

\section{Summary of Fit}

\begin{tabular}{|c|c|}
\hline Rsquare & 0.868793 \\
\hline RSquare Adj & 0.863636 \\
\hline Root Mean Square Error & 0.857746 \\
\hline Mean of Response & 8.817485 \\
\hline Observations (or Sum Wgts) & 239 \\
\hline
\end{tabular}

\section{Analysis of Variance}

\begin{tabular}{|c|c|c|c|c|}
\hline Source & DF & Sum of Squares & Mean Square & F Ratio \\
\hline \hline Model & 9 & 1115.6081 & 123.956 & 168.4813 \\
\hline Error & 229 & 168.4817 & 0.736 & Prob > F \\
\hline C. Total & 238 & 1284.0898 & & $<.0001$ \\
\hline
\end{tabular}

variables, the effect of a percentage change in any variable on the demand can be determined. For example, the price elasticity of air passenger demand as shown in the following equation is approximately -1.05 which implies that if price decreases by $1 \%$, air passenger demand would increase by $1.05 \%$. This means that domestic air travel demand shows a slightly elastic behavior in Turkey.

The semi-logarithmic regression model can be expressed as follows:

$$
\begin{aligned}
\operatorname{LogPax}_{i j}= & 5.095-1.050 \operatorname{LogPrc}_{i j}+0.327 \operatorname{LogPop}_{i j}+ \\
& 0.093 \operatorname{LogBed}_{i j}+0.585 \operatorname{Trm}_{i j}-0.146 \operatorname{Ttm}_{i j}- \\
& 1.893 \operatorname{Trt}_{i j}+0.959 \mathrm{Cnt}_{i j}+0.188 S c d_{i j}+0.001 \text { Dst }_{i j} .
\end{aligned}
$$

This finding is consistent with the fact that after low cost carriers entered into the domestic market, price war has begun and market size has considerably grown. The elasticity level implies that domestic air passenger traffic grows higher than the decreasing rate of ticket price. Hence, low fare policy is generally recommended for those air carriers which seek for higher load factor on a flight route since total revenue is expected to increase inspite of lower price as a result of elastic demand. It can be observed that all

\begin{tabular}{|c|c|c|c|c|c|c|}
\hline Research Name & $\begin{array}{l}\text { Level of } \\
\text { Forecast }\end{array}$ & Reference & Year & Independent Variables & Observation & $\begin{array}{l}\text { Adjusted } \\
\text { R Square }\end{array}$ \\
\hline Demand For Air Transport In Nigeria & Aggregate & [18] & 2010 & $\begin{array}{c}\text { Index of Agriculture } \\
\text { Index of Electricity } \\
\text { GDP }\end{array}$ & 23 & 0.923 \\
\hline $\begin{array}{l}\text { Air Travel Domestic Demand } \\
\text { Model in Bangladesh }\end{array}$ & Aggregate & [7] & 1998 & $\begin{array}{l}\text { Population } \\
\text { GDP } \\
\text { Distance }\end{array}$ & 31 & 0.88 \\
\hline $\begin{array}{c}\text { An Econometric Analysis of } \\
\text { Air Travel Demand in Saudi Arabia }\end{array}$ & Aggregate & [6] & 2001 & $\begin{array}{l}\text { Population } \\
\text { Total Expenditures }\end{array}$ & 25 & 0.959 \\
\hline Demand for Air travel In USA & O\&D & [2] & 2003 & $\begin{array}{c}\text { Density, Interaction, } \\
\text { Distance, Market share, Fare }\end{array}$ & 2424 & 0.57 \\
\hline An Aggregate Demand Model in Hub-and-Spoke & Aggregate & [8] & 2006 & $\begin{array}{l}\text { Frequency, Number of Spokes, Fare, } \\
\text { Distance, Capacity, Traffic Type }\end{array}$ & 897 & 0.792 \\
\hline
\end{tabular}
independent variables have positive impact on air passenger

Table 6. Model Efficiency Benchmark 
Table 7. Parameter Estimates

\begin{tabular}{|c|c|c|c|c|c|}
\hline Term & Estimate & Std Error & t Ratio & $\operatorname{Prob}>|t|$ & VIF \\
\hline Intercept & 5.0953283 & 1.808305 & 2.82 & 0.0053 & - \\
\hline Trm & 0.5854434 & 0.273002 & 2.14 & 0.0330 & 1.2649877 \\
\hline $\mathrm{Ttm}$ & -0.146405 & 0.0363 & -4.03 & $<.0001$ & 3.2119283 \\
\hline Trt & -1.893718 & 0.188805 & -10.03 & $<.0001$ & 2.2478437 \\
\hline Cnt & 0.9592384 & 0.088819 & 10.80 & $<.0001$ & 1.6655125 \\
\hline $\log (\operatorname{Prc})$ & -1.050123 & 0.363063 & -2.89 & 0.0042 & 1.226691 \\
\hline Scd & 0.1878425 & 0.038815 & 4.84 & $<.0001$ & 1.1054137 \\
\hline Log(Pop) & 0.3270246 & 0.068732 & 4.76 & $<.0001$ & 3.2572982 \\
\hline $\log (\mathrm{Bed})$ & 0.0934883 & 0.032053 & 2.92 & 0.0039 & 1.5998215 \\
\hline Dst & 0.0012053 & 0.000166 & 7.28 & $<.0001$ & 1.2778102 \\
\hline
\end{tabular}

demand estimation, except price, travel time and transit. The coefficient of the dummy variable transit implies that if any city pair does not include a direct service, air passenger demand would be $89 \%$ less likely than the city pair with direct service. This indicates that availability of direct air services is stimulating additional passenger traffic for city pairs.

Another result is that airlines competition in each O\&D market is significantly contributing to the air transportation demand. Competition leads variation in prices, and consequently, consumer surplus reaches higher level once airlines try to attract more passengers by lowering prices. Price war and more frequent flights are the key factors to enlarge the market size because low fare policy enables airlines to stimulate air passenger demand in addition to shifting more passengers from other modes of transportation.

Lastly, the macroeconomic factors such as urban population, distance and the number of beds in tourism facility are also found to be significant drivers for domestic air transport demand.

\section{a. Actual versus Predicted}

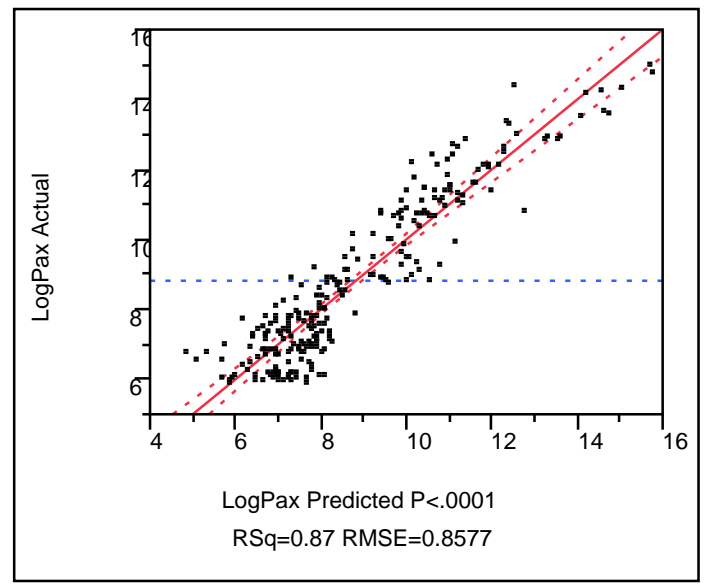

\section{Prediction Performance}

In Fig. (1a), model fit of the experimental data is shown as a scatter diagram. The scatterplot and fitted line in the figure suggest a linear pattern. In Fig. (1b), the fitted values of $\log (\operatorname{Pax})$ are on the horizontal axis and the residuals are on the vertical axis. Points are scattered evenly above and below the horizontal line at 0 , without any sign of curvature.

A test data obtained from 2010 traffic results consist of 213 observations. In Table 8, it is shown that the model predicts 2010 figures with a MAPE (Mean Absolute Percentage Error) value $8.5 \%$ and with a RMSE (Root Mean Square Error) value 0.942. Air Passenger Traffic has grown by $15 \%$ in 2011 comparing with previous year. Geoeconomics progress is only unable to explain such significant increase in the airline industry. Therefore, airline service related factors in conjunction with its business strategy and practices seem to be distinguishing drivers for fluctuation in air travel demand. However, actual air passenger traffic may not go in parallel with potential air travel demand on a flight route. In other words, product and services supplied by airlines may be insufficient to cultivate market potential in

\section{b. Residual Fit}

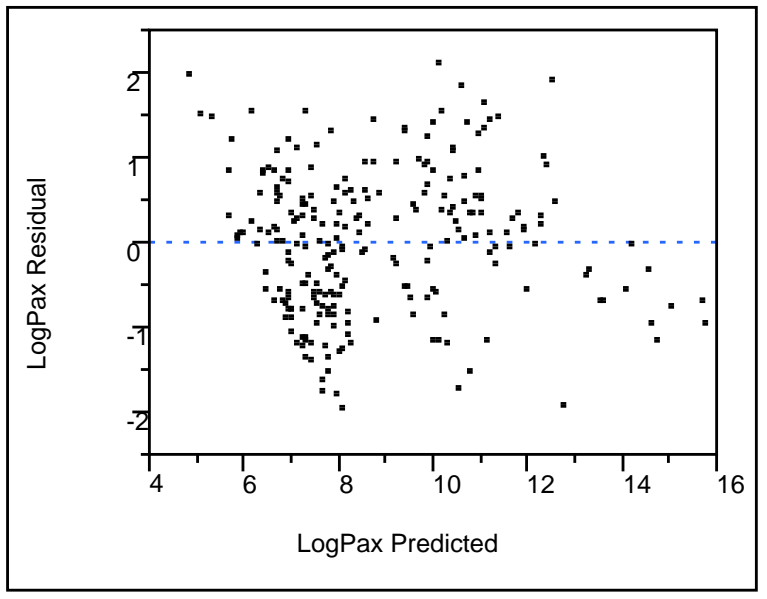

Fig. (1). Prediction Model. 
depth. For example, if flight choices are not wide, or bidirectional connections are missing, or ticket prices are high due to monopolistic market situation then it would not be quite possible to convert potential customer into actual passenger. This fact may lead geo-ecomomics factors stay latent in the model for a flight route on which unsatisfactory service is offered by airlines. In order to exploit potential market demand, competition is the best policy which urges airlines to offer competitive product and services satisfying customer need.

Table 8. Prediction Performance

\begin{tabular}{|c|c|c|c|c|}
\hline Year & Actual Pax & N Rows & MAPE & RMSE \\
\hline \hline 2011 & 24.699 .123 & 239 & $8.3 \%$ & 0.858 \\
\hline 2010 & 21.398 .616 & 213 & $8.5 \%$ & 0.942 \\
\hline
\end{tabular}

\section{CONCLUSION}

The semi-logarithmic regression model for the estimation of domestic passenger volume between domestic cities in Turkey is examined in this study. By assuming unavailable servicerelated or market specific input variables, and using crosssectional calibration data, the model is particularly applicable to city-pairs where no air service exists, no historical data are available, or factors describing the current service level of air transportation are not available.

This study demonstrated that the studied econometric estimation using micro level data based on local area information can result in substantial insights to O\&D travel. The demand model reveals all the quantitative relationships among the independent variables, which are helpful for airlines or other relevant aviation companies to understand the consequences of changes in their decision variables or adjustment of their routing structures. It is also useful for the related authority to quantify the benefits of airport capacity expansion or to predict potential air travel demand for a new airport.

Better conclusions could be drawn if the time period covered by the analysis is extended. This would enable us to examine possible differences in elasticity amongst city-pairs. Extending the data back in time would also provide observations on the effects of airfare progress. In addition to longer time period, it is expected that embedding market size of alternative modes of transportation for each city pair into model will most likely contribute model accuracy. Air travel demand in Turkey has shown a twofold growth: first is traffic shift from the bus companies and second is induced demand resulting in proliferation of more frequent flyers due to more affordable ticket prices.

The prediction efficiency could be improved by utilising an artificial neural network (ANN) model which, given its universal function approximation capability, is a perfect tool for building such complex models. Furthermore, bigger number of explanatory variables may significantly improve prediction performance knowing that ANN can overcome with correlated independent variables due to its nonlinear aspect.

\section{CONFLICT OF INTEREST}

The authors confirm that this article content has no conflict of interest.

\section{ACKNOWLEDGEMENTS}

Declared none.

\section{REFERENCES}

[1] R. T. Carson, T. Cenesizoğlu, and R. Parker, "Aggregate demand for USA commercial air travel", Int. J. Forecasting, vol. 27, pp. 923-941, 2011.

[2] D. Bhadra, "Demand for air travel in the United States: Bottom-up econometric estimation and implications for forecasts by origin and destination pairs", J. Air Transp. Manag., vol. 8, pp. 19-56, 2003.

[3] S. C. Wirasinghe and A. S. Kumarage, "An aggregate demand model for intercity passenger travel in Sri Lanka", Transportation, vol. 25, pp. 77-98, 1998.

[4] M. Brons, E. Pels, P. Nijkamp, and P. Rietveld, "Price elasticities of demand for passenger air travel", J. Air Transp. Manag., vol. 8, pp. 165-175, 2002.

[5] D. U. Asri, and Y. Sugie, "Simultaneous demand model for passenger travel: A case study of Indonesia”, East. Asia Soc. Transp. Stud., vol. 4, pp. 869-884, 2003.

[6] S. Y. Abed, A. O. Ba-Fail, and S. M. Jasimuddin, "An econometric analysis of international air travel demand in Saudi Arabia", J. Air Transp. Manag., vol. 7, pp. 143-148, 2001.

[7] J. B. Alam, and D. M. Karim, "Air travel demand model for domestic air transportation in Bangladesh", J. Civil. Eng., vol. 26, pp. 1-13, 1998.

[8] W. Wei and M. Hansen, "An aggregate demand model for air passenger traffic in the hub and spoke network", Transp. Res. A., vol. 40, pp. 841-851, 2006.

[9] A. O. Ba-Fail, "Applying data mining techniques to forecast number of airline passengers in Saudi Arabia (domestic and international travels)", J. Air Transp., vol. 9, pp. 100-116, 2004.

[10] A. O. Ba-Fail, and S. Y. Abed, "The determinants of domestic air travel demand in the Kingdom of Saudi Arabia", J. Air. Transp. Worldw., vol. 5, pp. 72-86, 2000.

[11] T. Grosche, F. Rothlauf, and A. Heinzl, "Gravity models for airline passenger volume estimation", J. Air Transp. Manag., vol. 13, pp. 175183, 2007.

[12] J. Dargay, and M. Hanly, "The determinants of the demand for international air travel to and from UK", ESRC Transport Studies Unit, Centre for Transport Studies, University College: London, vol. 59, pp. 1-14, November 2001.

[13] K. W. Kim, H. Y. Seo, and Y. Kim, "Forecast of domestic air travel demand change by opening the high speed rail", KSCE J. Civil Eng., vol. 7, pp. 603-609, 2003.

[14] C. Wu, J. Han, and Y. Hayashi, "Airport attractiveness analysis through a gravity model: A case study of Chubu International Airport in Japan”, CD-ROM (100350), East. Asia Soc. Transp. Stud., vol. 8, June 2011.

[15] R. A. Ippolito, "Estimating airline demand with quality of service variables”, J. Transp. Econ. Policy, vol. 15, pp. 7-15, January 1981.

[16] F. Kopsch, "A demand model for domestic air travel in Sweden", J. Air Transp. Manag., vol. 20, pp. 46-48, 2012.

[17] J. D. Jorge -- Calderon, "A demand model for scheduled airline services on international European routes", J. Air Transp. Manag., vol. 3, pp. 23-35, January 1997.

[18] A. J. Aderamo, "Demand for air transport in Nigeria", J. Econ. vol. 1, pp. 23-31, 2010. 